\title{
A RUNNER'S MEDITATION
}

I saw a muskrat in the park

chewing grasses with perfect attention

in a pool of sunlight that

turned gold the tips of her

glistening chestnut hair.

I'd seen her before at just the end of dark

swiming the shallow strearn that winds

through the park; just a smooth parting of the water;

then her endearing waddle as she

brought from the bank the right twig,

longer than herself and fringed in new leaves.

Grasping it firmly in delicate jaws

she melted into the water

and swam again and with a flip disappeared

into a hole in the bank.

I was pleased to know she was there going about her business, and confident in her wisdom

to come out only before dawn,

before joggers and dog-walkers,

before anxious mothers could cry "RAT!"

to the park authorities in their ill-fitting green costumes.

Today she sits in the sun,

civil and lovely.

surely she deserves to sit in the sun.

Does she think people so kind?

The park is in a town.

I fear for her and murnur a sacred name

in blessing as I pass.

In the path before me

lies a flower. I pick

it up. Its lavender petals

are nylon.

Its yellow stamen

plastic--

flung there no doubt

to mock the bees.

PAULETTE CALLEN 